\title{
História da cidade, consciência histórica e jovens escolarizados: o caso de Curitiba
}

\author{
City's history, historical consciousness and high school \\ students: the case of Curitiba
}

Geyso Germinari*

RESUMO

O artigo tem como tema a relação entre a história da cidade, a consciência histórica de jovens escolarizados e a formação de identidades acerca da cidade de Curitiba-Pr. O objetivo da investigação foi analisar de que forma a consciência histórica de jovens escolarizados que vivem em Curitiba expressa suas identidades em relação à cidade de Curitiba. O estudo enquadra-se no domínio científico da Educação Histórica, cuja atenção volta-se ao conhecimento sistemático das ideias históricas de alunos e professores, tendo como referência principal à teoria da história de Jörn Rüsen, particularmente, a ideia de consciência histórica, que, segundo este autor, articula o passado como experiência e o presente e o futuro como campos de ação orientados pelo passado, e tem como funções essenciais a orientação temporal e a criação de identidades individuais e coletivas.

PALAVRAS-CHAVE: Educação Histórica. KEY-WORDS: History Education. Historical Consciência histórica. J ovens escolarizados.
ABSTRACT

The article has as its theme the relationship between the city's history, the historical consciousness of young educated and the formation of identities concerning the city of Curitiba-Pr. The purpose of this investigation was to examine how the historical consciousness of young educated who live in Curitiba express their identities in relation to the city of Curitiba. The study fits into the scientific field of History Education, as our attention turns to the systematic knowledge of the historical ideas of students and teachers, referenced mainly by the J örn Rüsen theory of history, particularly the idea of historical consciousness, which according to this author articulates the past as experience and present and future as fields of action oriented by the past, and has the essential functions the temporal orientation and the creation of individual and collective identities. consciousness. Educated youth.

\section{Introdução}

O objetivo deste trabalho é refletir sobre a relação entre História da cidade e a formação da consciência histórica de jovens escolarizados. As inquietações com os caminhos da História ensinada já estavam presentes na minha dissertação de mestrado, desenvolvida no Programa de Pós-Graduação em Educação, da UFPR. Esta pesquisa discutiu a possibilidade da utilização de documentos em estado de arquivo familiar em aulas de história, nas séries iniciais, do ensino fundamental. Esses documentos não fazem parte da vida de pessoas que tiveram algum destaque público

\footnotetext{
* Doutor em Educação pela Universidade Federal do Paraná, Brasil.

Laboratório de Pesquisa em Educação Histórica do PPGE/ UFPR . Email: geyso@pop.com.br
} 
no cenário político, ou algo considerado importante para a sociedade podem ser encontrados no interior das mais diversas residências, arquivados em gavetas, em caixas de papelão, esquecidos temporariamente em cima de armários.

Nessa investigação, desenvolvi uma pesquisa de campo de natureza qualitativa, com duas professoras das séries iniciais, do ensino fundamental, de uma escola pública, da rede de ensino do município de Pinhais-Pr. Os dados coletados em entrevistas e documentos, planos de aula e currículo do município permitiram indicar elementos da transposição didática da história, quando o professor das séries iniciais utiliza em suas aulas os documentos em estado de arquivo familiar.

As professoras, ao usarem os documentos em estado de arquivo familiar, expressaram nas discussões ideias que se relacionavam com as seguintes dificuldades de natureza teórico-metodológica: a) trabalhar a participação dos sujeitos; b) relacionar a história local com a história geral; c) desenvolver a noção de temporalidade histórica; d) desenvolver trabalhados coletivos.

Nos últimos anos, tomei contato com um debate que se inicia no Brasil: a Educação Histórica. Esses debates resultam da comunicação entre professores brasileiros e professores de outros paises, principalmente da Inglaterra e Portugal.

A perspectiva da Educação Histórica difere da forma da "transposição didática" do conhecimento histórico em conhecimento histórico escolar. Segundo Schmidt (2006, p. 4107) a proposta da transposição didática da História,

[...] não levou em consideração, [...], o fato de que o método de ensino pressupõe uma relação intrínseca com o método e a filosofia da própria ciência, o qual delimita, não somente os objetivos e finalidades do ensino, mas também a sua forma de ensinar. Pelo contrário, a transposição didática do conhecimento histórico em conhecimento escolar pautou-se, sobretudo, na imposição dos aspectos psicológicos e pedagógicos. Esse pode ser um dos fatores que afastaram tanto 'a história dos professores e a história dos historiadores'.

Um dos princípios constitutivos da Educação História, enquanto campo de ação e investigação, é de ordem teórica e diz respeito à relação intrínseca do ensinar História com o método e a filosofia da ciência histórica.

Nessa direção, no doutorado as minhas reflexões sobre aprendizagem e ensino de História localizam-se no interior dos debates internacionais da Educação Histórica e nas pesquisas sobre a Didática da História desenvolvidas no Laboratório de Pesquisas em Educação Histórica, na Linha de Pesquisa Cultura, Escola e Ensino, do Programa de Pós-Graduação em Educação, da Universidade Federal do Paraná. Tais investigações têm como foco compreender as ideias históricas de alunos e professores. 
O ensino de História constitui-se hoje como um fértil campo de investigação, sendo objeto de pesquisa sob diversos ângulos que integram quer perspectivas diacrônicas quer a análise de problemáticas actuais do ensino específico. É dentro desta segunda perspectiva que a investigação sobre cognição e ensino de História freqüentemente denominada investigação em educação histórica tem-se desenvolvido com pujança em vários países [...].

Minha preocupação agora se volta para a relação entre história local, formação da consciência histórica de jovens escolarizados e a constituição de suas identidades, pois uma das considerações do trabalho de mestrado foi indicação da necessidade do desenvolvimento de pesquisas sobre a relação de alunos com a história local.

Nessa direção, busquei no doutorado procurei compreender como os jovens escolarizados que cursam o primeiro ano do ensino médio de escolas públicas de Curitiba possuem, em suas consciências histórias, elementos sobre a história da cidade de Curitiba, bem como explicitar a relação desses elementos com a formação das suas identidades.

A pesquisa foi desenvolvida dentro do domínio científico da Educação Histórica, tendo particularmente como referências os estudos sobre consciência histórica de jovens. Segundo Barca (2009, p. 53):

Na pesquisa recente em Educação Histórica a busca de elementos para a compreensão da consciência histórica, em especial a dos jovens, constitui-se como um dos objetos centrais de pesquisa com a intenção de reunir dados empíricos que possibilitem um melhor entendimento acerca das idéias e usos de história, no quotidiano das pessoas mais ou menos letradas historicamente.

\section{O Desenvolvimento da Pesquisa}

No primeiro momento, analisei a trajetória e os resultados das pesquisas sobre consciência histórica de jovens.

As investigações que tratam o tema da consciência histórica vêm sendo desenvolvidas a partir de diferentes perspectivas. Nesse sentido, apresentam-se como possibilidades as pesquisas comparativas interculturais baseadas na aplicação de questionários fechados e/ ou abertos (ANGVIK; BORRIES, 1997), o inquérito do projeto Youth and History e a análise de narrativas históricas e de outros materiais de estudantes. Conforme afirma Rüsen (2001) as abordagens teórico-metodológicas da consciência histórica precisam levar em conta que esta consciência se expressa em 
narrativas estruturadas do passado, cuja coleta e análise das ideias dos sujeitos investigados são a base para o estudo desse tema, qualquer que seja o método empregado.

As pesquisas sobre consciência histórica de jovens tiveram origem na Alemanha, no contexto da unificação entre a República Democrática Alemã (RDA) e a República Federal da Alemanha (RFA). No início da década de 1990 mudanças estruturais transformaram o cenário político internacional, levando à reorganização da economia mundial. Os principais acontecimentos foram o fim da guerra fria, com o colapso do bloco socialista, desintegração da URSS e a unificação da Alemanha, simbolizada pela queda do Muro de Berlim.

A difusão generalizada do termo "reunificação", para representar a união da Alemanha, trazia a ideia da incorporação da RDA à RFA. Em outras palavras, o estado unificado deveria seguir o modelo político e econômico capitalista da Alemanha Ocidental (RFA). Com desenvolvimento da "reunificação", chegou-se à conclusão na Alemanha Ocidental que a história da Alemanha Oriental poderia desaparecer.

De acordo com Jung e Staher (1998, p. 133):

\begin{abstract}
O não reconhecimento da história da Alemanha oriental como parte da historia global alemã desde 1945/49, junto com a experiência da supremacia política e econômica da RFA, produziu o fato de que desde 1994 começou a parecer uma nova identidade germanaoriental. Lentamente se irá reconhecendo que a reconstrução da história da RDA como parte da história da Alemanha em seu conjunto constituía um requisito essencial para o futuro auto-determinado da Alemanha unificada.
\end{abstract}

Na Alemanha, na década de 1990, as condições da aprendizagem da história foram profundamente influenciadas pelos problemas gerados pela reunificação. As novas condições administrativas que passaram a reger o ensino de História nas escolas evidenciavam a existência de um esforço de instrumentalizar o ensino, sob tutela ideológica da Alemanha Ocidental.

As concepções de ensino de História tinham como base conceitos didáticos diferentes, os quais geravam práticas de ensino e pesquisa diferentes. Diante da realidade da unificação, professores e pesquisadores dos dois Estados tiveram que encontrar um modo de ensino e aprendizagem de História adequada à nova situação política e social.

Na Alemanha ocidental o ensino de História era marcado pelo compromisso com a investigação teórica sobre os efeitos sociais da história ensinada em uma sociedade plural, tanto na política como na ciência. Por outro lado, a Alemanha oriental 
priorizou os aspectos metodológicos do ensino de História, determinados pelo Estado. “Dado que na RDA a doutrina estatal marxista-leninista não permitia controvérsias científico-históricas tampouco havia posições divergentes acerca da didática da história, como na RFA". (J UNG; STAHER, 1998, p. 135).

Nesse contexto, a formação dos professores de História também era diferente. Na Alemanha oriental a formação era essencialmente voltada à pedagogia, com foco especial na parte instrumental do ensino. Os chamados "metódicos da história" discutiam questões de métodos de ensino, psicologia da aprendizagem e desenvolvimento das classes sociais. Além disso, mantinham permanente relação com as escolas, uma vez que também eram responsáveis pela formação continuada dos professores. A Alemanha ocidental privilegiou a formação histórica dos seus professores.

De acordo com J ung e Staher (1998, p. 135),

Por conseguinte, se desenvolveu na RDA um entendimento teoricista da metodologia da história. Estes pontos fortes da metodologia da história na RDA foram ignorados no ocidente. Em vez disso se incidiu na função de apoio ao sistema uma consistente formação políticoideológica dos escolares. Assim foram demitidos todos os professores integrantes da metodologia da história.

Nessa conjuntura, havia o entendimento de que o ensino de História praticado na antiga RDA se transformaria profundamente de acordo com as normas didáticas que imperavam na RFA.

Depois da unificação foram desenvolvidos cursos de preparação dos professores, neles trabalhava-se a visão ocidental sobre a história da RDA, após 1945, com as correspondentes consequências curriculares para a aprendizagem histórica e o método de trabalho em sala de aula. Contudo, nem professores e nem os metódicos da RDA abandonaram seu campo de ação, sem propor iniciativas próprias. Como afirmam J ung e Staher (1998, p. 137),

Já em junho de 1990, alguns meses antes da unificação, os 'metódicos da história' decidiram em seu último congresso rebatizar-se como didatas da história. Assim, documentaram a sua vontade de reorientar-se para a didática da história da Alemanha Ocidental, que na época era fortemente tendenciosa e idealizada.

A aproximação entre os didatas da história das antigas RDA e RFA, se caracterizou pela aceitação generalizada da categoria de "consciência histórica”, 
em detrimento do conceito de identidade nacional. Conforme Jung e Staher (1998, p. 138-139),

O curto debate sobre a validade da "emancipação" ou seja, sobre o alcance da "identidade nacional" como idéia-guia da aprendizagem histórica diminuiu sem grandes controvérsias graças a aceitação da categoria relativamente indeterminada de "consciência histórica". Além de evitar conflitos se obteve, um benefício: a didática da história deve integrar a função, a morfologia, a gênesis, assim como a construção e a remodelação das consciências históricas que se pode encontrar na sociedade. Através do ensino, os escolares devem formar uma consciência história na qual se relacionem passado, presente e futuro, de tal modo que pode obter-se uma orientação presente e futura. A categoria de consciência histórica é, por isto, meramente formal, o que explica sua capacidade de consenso.

A categoria "consciência histórica" foi incorporada com o objetivo principal de formação histórica dos estudantes alemães. Esta categoria foi referenciada principalmente nos estudos do filósofo da história alemão Jörn Rüsen. Para este autor, a consciência histórica é a consciência da relação estrutural entre passado, presente e futuro. A formação dessa consciência não se produz unicamente na escola, mas também em outros espaços da sociedade. Nessa perspectiva, a Didática da História, como área específica de reflexão e intervenção sobre o ensino-aprendizagem expandiuse para novos lugares, como os museus, arquivos, mídias (literatura, televisão, cinema), viagens, meio familiar, âmbitos tradicionalmente negligenciados como elementos didáticos.

Além do trabalho de delinear a definição da categoria consciência histórica, como elemento principal da formação histórica, também foram apresentados estudos empíricos com alunos e professores.

Os resultados de uma das investigações desenvolvidas com alunos da Alemanha (oriental e ocidental), e da Europa do leste e oeste, surpreenderam os investigadores, quando concluíram que não havia grandes diferenças entre a consciência histórica dos alunos orientais e ocidentais. Sobre esse estudo, J ung e Staher (1998, p. 140) dizem que

Pelo que se refere à estrutura da consciência histórica, que aqui há sido novamente dimensionada (informação técnica, capacidade de crítica, orientação sobre os valores básicos) se evidenciou que os alunos medem majoritariamente os personagens e os acontecimentos históricos segundo uma escala de valores atual, e que a capacidade de compreensão do foráneo esta muito debilmente desenvolvido.

Outra investigação realizada com mais de 6000 estudantes dos estados da Alemanha ocidental e de cinco estados da Alemanha oriental e com professores de 
história demonstrou resultados semelhantes. Destes resultados, segundo J ung e Staher (1998, p. 140), o investigador Bodo Von Borries extraiu algumas consequências para o ensino de história: “a) Elementarización de la gradación de la enseñanza; b) Intensificación de los métodos; c) Fomento de la comprensión hacia lo extranjero; d) Estimulación de la reflexión".

Depois dos primeiros estudos, outras pesquisas foram desenvolvidas em vários paises, também baseadas no conceito de consciência histórica delineado por Rüsen. Segundo Schmidt e Garcia (2005, p. 118),

Nestas pesquisas, não se trata de analisar programas de manuais, para se presumir os efeitos no ensino de História, mas de pesquisar estes efeitos nos sujeitos que foram objeto de ensino. Também não têm como fonte de pesquisa apenas os saberes escolares, mas outras fontes como a família, os mídia, as circunstâncias da vida das pessoas, as quais são consideradas igualmente importantes para aprendizagem histórica.

A maior pesquisa deste gênero foi realizada no continente europeu no final da década de 1990. Um grupo de pesquisadores de vários países sob coordenação do norueguês Magne Angvik e do alemão Bodo von Borries estruturou o projeto Youth and History. A referência principal do projeto foram às investigações interculturais de Borries desenvolvidas no âmbito da Didática da História e os estudos teóricos de Rüsen sobre a consciência histórica.

A pesquisa organizada no formato survey tinha como objetivo responder questões sobre as características, qualidade e resultados do ensino de História e, particularmente, sobre a configuração geral da consciência histórica dos jovens europeus.

A investigação buscou identificar e avaliar o conceito de consciência histórica na perspectiva de jovens de 15 anos e seus professores em 25 países europeus, mais Israel, Palestina e Turquia, os quais responderam um questionário, com perguntas sobre conteúdos, métodos de ensino e concepções de História e cidadania. O levantamento de dados foi de amplo alcance e contou com 32.000 respondentes. Em cada país foram aplicados, em média, 800 a 1200 questionários, nas salas de aula, durante o horário da aula de história.

O questionário abordou vários temas, além de informações para contextualizar cada indivíduo. Os estudantes responderam questões sobre a concepção e importância da História; confiança em fontes de conhecimento histórico; cotidiano das aulas de história; conhecimentos cronológicos de fatos históricos; interesses por gêneros e períodos históricos; interesse pela história por área geográfica; conceito de mudança 
histórica; representações atribuídas a personagens e períodos históricos; concepção de temporalidade histórica; concepções de passado e expectativas de futuro pessoal e nacional; preservação do patrimônio; fatores da divisão do país em classes; perguntas sobre tomada de decisão pessoal em se vivendo situações passadas e futuras (como o pagamento de indenização pela colonização das nações africanas, por exemplo); concepções de nação e estado), nacionalidade e soberania sobre um território e posição política sobre questões de urgência nos países ou na Europa em geral (como por exemplo, energia nuclear e armamento bélico). Os temas desdobraram-se em perguntas sistematizadas como afirmações, as quais os jovens responderam um dos itens colocados em uma escala de valoração, que iniciava com "discordo totalmente" até "concordo totalmente", passando por "discordo", "sem opinião" e "concordo".

Os professores responderam perguntas relacionadas à contextualização do indivíduo nos países, experiência de ensino em anos, formação acadêmica, estudos desenvolvidos no campo da História, informações sobre sua prática de ensino de História, particularidades do currículo de História, avaliação da capacidade cognitiva dos alunos, significado da religião para vida do professor, interesse por política para o cotidiano do professor, conceitos históricos (nação, democracia, Europa, integração européia) trabalhados em sala, questões de método de ensino-aprendizagem, objetivos do ensino de História, fatores de mudança históricas consideradas mais relevantes e projeções de futuro quanto a fatores de mudança histórica.

Segundo Barca (2007, p. 117), os pesquisadores Angvik e Borries (1997):

[...] reconheceram que as idéias manifestadas pelos jovens de 15 anos em diversos países europeus acerca do passado, presente e futuro são o espelho da mentalidade dos respectivos povos: se os jovens de países mais industrializados se mostram mais críticos face ao passado, os de países com economias mais tradicionais assumem uma postura de maior aceitação e até de entusiasmo face ao estudo da História.

Esta constatação remete à ideia de que a consciência histórica é culturalmente variável, em outras palavras, mudando o contexto cultural mudam as relações entre as interpretações do passado, percepções do presente e expectativas do futuro. $\mathrm{Na}$ perspectiva de Angvik e Borries (1997), é plausível pensar a existência de uma intricada relação entre cultura e consciência história, porém, tal relação está longe de ser mapeada em todos os seus detalhes. Pais (1999, p. 3) corrobora com Angvik e Borries (1997), em suas palavras, 
Embora a consciência histórica seja discursivamente representada, cientificamente interpretada e teoricamente explicada, e apesar de genérica ou vagamente se sustentar que ela depende da "cultura", não há referências empíricas fidedignas sobre a formação da consciência histórica entre as jovens gerações.

As discussões de Rüsen (2001) sobre a relação da consciência história e a vida prática contribuem na problematização da questão colocada por Angvik e Borries (1997) e Pais (1999). A partir do pensamento de Rüsen (2001), pode-se afirmar que a realidade do jovem se expressa na consciência história, e que, de alguma maneira, os elementos que constituem a vida do jovem estão presentes na sua consciência histórica. Nessa direção, conhecer as estruturas identidárias presentes na cultura juvenil pode revelar aspectos da relação entre cultura e consciência histórica.

A participação portuguesa no projeto Youth and História, coordenada por Pais (1999), contou com a aplicação do inquérito principal numa amostra nacional de alunos do 9o ano, cerca de 1200 jovens, durante as aulas da disciplina de História. Como nos outros países também foram inquiridos os respectivos professores de História. A investigação ainda recorreu a outros instrumentos de pesquisa. Segundo Pais (1999, p. 9),

Paralelamente à aplicação deste instrumento de inquirição extensiva o questionário fechado - fiz uso de metodologias qualitativas ou indiciárias, envolvendo, principalmente, entrevista aprofundadas a professores e estudantes de História. Nalguns casos, fiz reuniões informais de grupo de modo a produzir uma situação de comunicação que favorecesse a captação, entre alunos e professores, de representações simbólicas sobre a História e o seu ensino. Desejava também ver como a consciência histórica - sendo uma forma de consciência social - acabaria por emergir num contexto grupal, propiciador do surgimento de categorias e interpretações geradas numa base hermenêutica e dialógica, ainda que sob forma discursiva.

Os resultados da investigação portuguesa foram sistematizados no livro Consciência história e identidade: os jovens portugueses num contexto europeu, de autoria de José Machado Pais (1999). A obra comporta três partes principais. A primeira destinada à aprendizagem da História e suas imagens, começa aferindo sobre algumas representações dos jovens europeus, em particular dos jovens portugueses, sobre o significado da história e seus objetivos. Na parte dois, consagrada à temporalidade e a mudança histórica, os jovens são confrontados com várias representações do tempo, e também com fatores de mudanças dos tempos presente e do futuro próximo. A terceira parte trata das atitudes e representações sociais que se expressam na consciência histórica dos jovens, onde foram analisadas opiniões dos 
jovens sobre juízos históricos relacionados a desigualdades sociais; desvalorização do patrimônio histórico; conflitos políticos (direito dos imigrantes, por exemplo); atitudes políticas que se prendem aos conceitos de nação/ Estado, Europa/integração europeia e democracia; atitudes sobre a vida presente e expectativas de futuro.

A obra de Pais (1999) trata especialmente da relação entre consciência histórica e identidade, questão expressada no título e retomada em vários momentos do texto. Como este autor afirma:

Sem consciência histórica sobre o nosso passado (e antepassados...) não perceberíamos quem somos. Esta dimensão identidária - quem somos? emerge no terreno de memórias históricas partilhadas. Por isso, o sentimento de identidade - entendida no sentido de imagem de si, para si e para os outros - aparece associada à consciência histórica, forma de nos sentirmos em outros que nos são próximos, outros que antecipam nossa existência que, por sua vez, antecipará a de outros. Ao assegurar um sentimento de continuidade no tempo e na memória (e na memória do tempo), a consciência histórica contribui, deste modo, para afirmação da identidade individual e colectiva. É sabido que a História não tem um sentido independente daquele que os indivíduos lhe dão. Por isso, o estudo das formas de consciência histórica é uma forma de conhecimento que nos permite descobrir como os indivíduos vivem com os 'fantasmas' do passado e, simultaneamente, os utilizam como forma de conhecimento (PAIS, 1999, p. 1).

Portanto, as identidades individuais e coletivas construídas pelos jovens estariam intrinsecamente associadas a sua consciência histórica. Segundo Pais (1999, p. 2), “a consciência histórica é uma construção simbólica, do mesmo modo que a identidade comporta também um processo de apropriação simbólica do real". Nessa perspectiva, torna-se possível pela investigação científica da consciência histórica, produzir conhecimento útil sobre a vida dos jovens, pois a vida se expressa de alguma maneira na consciência histórica, e nela é possível apreender a vida dos seres humanos (RÜSEN, 2001). Pais (1999) buscou compreender a relação entre as dimensões identitárias individuais e coletivas da vida dos jovens, que se expressam em sua consciência histórica.

O problema colocado por Pais (1999) vem acompanhado da hipótese de que a consciência histórica dos jovens tem uma forma específica de "inscrição geracional". Em sua perspectiva, as afinidades e sentimentos que ligam os jovens a uma geração possibilitam a participação num destino comum: um passado lembrado, um presente vivido, um futuro esperado, em outras palavras, permite uma determinada consciência histórica. Para este autor, a consciência história dos jovens europeus e portugueses seria, muito provavelmente, constituída pela identidade geracional. 
Visto que o quadro conceitual proposto por Rüsen (2001) tem orientado as pesquisas sobre consciência histórica de jovens, procurei aprofundar a análise da relação consciência histórica e identidade a partir dos estudos deste autor. As contribuições para a discussão epistemológica acerca das relações da História com a vida prática têm possibilitado identificar alguns caminhos de análise da consciência histórica de jovens. De acordo com Rüsen (2001), por seu papel em nos orientar no tempo, a consciência história tem duas funções essenciais: orientação temporal da vida prática externa einterna.

A competência interna de orientar a vida prática denomina-se identidade histórica. A identidade histórica fornece à vida um sentido temporal de continuidade entre o passado, o presente e o futuro. Esse trabalho da consciência histórica realiza-se nas práticas de narração histórica. Ademais, Rüsen (2001) afirma que o arranjo das três dimensões temporais (passado, presente, futuro), pela narrativa histórica, assume formas diferentes conforme o quadro de referências de orientação cultural da existência humana, que incluem diferentes dimensões identidárias construídas ao longo da vida.

Tais compreensões exigiram a busca de um conceito de identidade adequado à concepção de consciência histórica de Rüsen (2001). Essa tarefa trouxe um desafio à investigação, uma vez que o conceito de identidade tem sido tratado com maior intensidade pelas perspectivas pós-modernas que, de maneira geral, negam a existência de ordem temporal compreensiva de tempo, incluindo passado, presente e futuro em uma mesma estrutura, e defendem a tese da descontinuidade temporal, em que o passado torna-se um elemento isolado sem nenhuma relação substancial com o presente o futuro (HALL, 2005). Tal perspectiva é incompatível com o conceito de consciência histórica de Rüsen (2001), pautado na ideia de coerência e unidade temporal. Diante disso, recorri às reflexões de Martuccelli (2007, p. 312), pois, de acordo com este autor, "la identidad se forjará por la búsqueda de um equilíbrio personal entre el passado y el presente, por una habilidosa amalgama entre componentes sociales y culturais y outras dimensiones más personales". Em outro momento, Martuccelli (2007, p. 309) destaca que a:

[...] diferencia de la estructura narrativa de la subjetividad, que apunta a construirse a distancia del mundo, la identidade aparece como una figura que tiende a establecer un arreglo estrecho entre sí y el mundo, articulando una unidad de sí. Gracias a esse trabajo, el indivividuo es el producto de una historia en la cual busca llegar a ser el sujeto.

A aproximação entre as reflexões de Martuccelli (2007) acerca da constituição da identidade pela narrativa e de Rüsen (2001) sobre o enlace entre narrativa, 
consciência histórica e identidade histórica é possível, pois ambos entendem que a identidade estrutura-se mediante um trabalho permanente de orientar a vida prática, buscando criar um sentido de unidade no tempo.

Tanto Martuccelli (2007) quanto Rüsen (2001) advogam que a identidade é uma dimensão essencial para que os homens não se percam nas transformações do mundo e de si mesmos. Pela identidade, seja ela histórica ou não, torna-se possível para os seres humanos estabelecerem uma autocompreensão coerente e unitária da vida, diante das mudanças sofridas no mundo. Outro ponto de convergência, entre os autores, é que a identidade se institui pela prática da narrativa.

Martuccelli (2007, p. 307) coloca a questão nos seguintes termos:

La identidade es um espacio donde el individuo se forja, por el relato, um sentimiento de continuidad a través del tiempo e, incluso a veces, um sentimento de coherencia interna que le permite tomarse narrativamente como um individuo singular, pero siempre com la ayuda de elementos sociais y culturais.

Rüsen (2001, p. 66-67) aborda a relação consciência histórica, narrativa, representação da continuidade e identidade, da seguinte forma:

[...] a consciência histórica constitui-se mediante a operação, genérica e elementar da vida prática, do narrar, com a qual os homens orientam seu agir e sofrer no tempo. Mediante a narrativa histórica são formuladas representações da continuidade da evolução temporal dos homens e de seu mundo, instituidoras, por meio da memória, e inseridas, como determinação de sentido, no quadro de orientação da vida prática humana.

Segundo Martuccelli (2007) o indivíduo institui o seu pertencimento no mundo pela prática da narrativa. Os indivíduos constituem suas identidades pelo ato de narrar a si mesmos. Nesse ato, recorre à diferentes tópicos narrativos para construir identidades que estabeleçam a coerência da sua personalidade e a continuidade da sua experiência no tempo. Martuccelli (2007) destaca que os tópicos narrativos são estruturados socialmente e emergem de tradições culturais enraizadas em um determinado contexto histórico e social.

Na perspectiva de Rüsen (2001), a narrativa, como expressão da consciência histórica, é uma forma de constituição de sentidos sobre o passado. A competência narrativa de "dar sentido ao passado" está relacionada à articulação de três qualidades do ato de narrar: experiência, interpretação e orientação. A competência de experiência supõe uma habilidade para viver experiências temporais. Isso implica na capacidade de percepção de contingência e diferenças no tempo, entre o passado, presente e futuro. 
Segundo Rüsen (1992), a narrativa histórica, como expressão da consciência histórica, organiza a unidade interna das três dimensões do tempo (passado, presente, futuro) através de um conceito de continuidade. Este conceito ajusta a experiência real do tempo às intenções e expectativas humanas. Fazendo isso, ela faz a experiência do passado se tornar relevante para a vida presente e influencia a configuração do futuro.

A partir dessa inferência, busquei entender a relação entre a ideia de Curitiba cidade modelo e a formação da consciência histórica dos jovens escolarizados. Conforme Schmidt (2002, p. 201), quando se pensa na relação consciência histórica e identidade,

[...] no caso especifico dos jovens brasileiros, residentes na cidade de Curitiba, Estado do Paraná, o envolvimento afetivo com a cidade não pode ser desconsiderado na medida em que há um forte markenting político em torno da valorização de Curitiba como cidade ideal, de primeiro mundo.

Deste modo, procurei compreender, com base em estudos sociológicos (GARCIA, 1997; SOUZA, 2001; OLIVEIRA, 2001) e historiográficos (OLIVEIRA, 2000), o processo de construção de uma determinada imagem da cidade de Curitiba, vinculada à ideia de cidade modelo de urbanização, entre as décadas de 1970 e 1990.

O arcabouço teórico construído orientou o percurso da investigação empírica de natureza qualitativa e interpretativa. Esta fase da pesquisa foi organizada em três etapas, respectivamente desenvolvida como estudo exploratório, piloto e principal. A técnica de coleta de dados consistiu na aplicação de um questionário semiestruturado em cada etapa. Esse encaminhamento metodológico possibilitou um maior controle dos dados coletados. No total, o trabalho de campo envolveu 174 jovens, de 5 escolas da rede pública estadual do Paraná, localizadas na região sul de Curitiba. O material empírico coletado possibilitou fazer algumas análises em relação às identidades dos jovens sobre a cidade de Curitiba e a relação com a formação da consciência histórica.

No tocante à relação dos jovens escolarizados com a cidade de Curitiba, constatei a existência de identidades individuais matizadas por elementos subjetivos e identidades coletivas que tomam como referência elementos sociais para definir o pertencimento à cidade.

A identidade coletiva manifesta-se em dois sentidos: por um lado, a maior parte dos jovens tem uma visão positiva da cidade: valorizam os parques, as áreas verdes, o transporte coletivo, o planejamento urbano e os espaços de lazer, ponto de vista fortemente marcado pela ideia de Curitiba cidade modelo de urbanização, criada pela administração pública, a partir da década de 1970. De outro lado, em menor escala, os 
jovens percebem uma cidade com problemas sociais, semelhantes aos sofridos por outras cidades, como a violência e a pobreza. Nessa direção, verifiquei que há, entre os jovens pesquisados, uma identidade coletiva fortemente matizada pelas ideias e valores difundidos pelos discursos que edificaram a "cidade modelo". Esta relação dos jovens com a cidade é influenciada, em certa medida, pelo processo de escolarização.

\section{O Estudo Principal}

O campo de pesquisa foi constituído de 3 escolas públicas estaduais de ensino médio (denominadas A, B e C), de Curitiba, e atingiu uma amostra de 126 jovens.

A escola A está localizada no bairro Cidade Industrial foi criada em 1979. No momento da investigação havia um total de 1024 alunos matriculados, distribuídos nas modalidades de ensino fundamental, médio, educação de jovens e adultos e educação especial. O questionário semiestruturado foi aplicado em 1 turma do primeiro ano do ensino médio, turno diurno. Participaram da atividade 29 jovens: 19 mulheres e 10 homens.

A escola B situa-se no bairro Umbará, região sul de Curitiba, com população aproximada de 14.595 habitantes. Uma parte da história do bairro está ligada às olarias de tijolos e fabricação de barricas de erva-mate. Na atualidade, a economia local concentra-se na extração de areia e construção civil. A escola contava com 1500 alunos, matriculados no ensino fundamental (diurno), médio (diurno e noturno) e educação de J ovens e adultos (noturno). A aplicação do questionário atingiu 35 jovens (19 mulheres e 16 homens), de 1 turma do primeiro ano, ensino médio, turno noturno.

A escola C localiza-se no bairro Sítio Cercado, também situado na região sul da cidade. Nesta região ocorreu o maior crescimento populacional da cidade nos últimos anos. Hoje conta com aproximadamente 140.0000 habitantes. A escola oferta as modalidades de ensino fundamental, médio e educação de jovens e adultos, nos três turnos, e contava na época da pesquisa, com 2500 alunos matriculados. O questionário foi aplicado em duas turmas (denominadas $\mathrm{X}$ e $\mathrm{Y}$ ) do primeiro ano do ensino médio, diurno. A turma $\mathrm{X}$ tinha 32 jovens (17 homens e 15 mulheres) e a turma $\mathrm{Y}$ tinha 30 jovens, dos quais 16 mulheres e 14 homens. No geral, dos 126 jovens participantes do estudo principal, 69 eram do sexo feminino e 57 do sexo masculino.

\section{A Análise}

Considerando que o estudo da história do município nas escolas públicas brasileiras ocorre prioritariamente nos anos iniciais do ensino fundamental, busquei, 
primeiramente, levantar indícios da história de Curitiba que os jovens pesquisados apreenderam nesse nível de ensino.

As investigações de Schmidt e Garcia (2001, 2005) indicam que na segunda metade da década de 1990, por iniciativa do Ministério da Educação (MEC), foram produzidos e divulgados os Parâmetros Curriculares Nacionais (PCN's), os quais indicaram os objetivos, os conteúdos e as orientações didático-metodológicas para o ensino na escola fundamental, nas diferentes áreas de conhecimento. A História privilegiou a história local e do cotidiano como eixos temáticos dos conteúdos para as séries iniciais.

Nos PCN’s a proposta de estudos de história local parte da preocupação “[...] de que os alunos ampliem a capacidade de observar o seu entorno para a compreensão de relações sociais e econômicas existentes no seu próprio tempo e reconheçam a presença de outros tempos no seu dia-a-dia”. (BRASIL, 2000, p. 51). As indicações dos documentos federais foram incorporadas, em certa medida, nas propostas estaduais e municipais. Os PCN's repercutiram de alguma forma na construção dos planos, projetos e programas das escolas brasileiras, na última metade dos anos 1990 (SCHMIDT; GARCIA, 2001).

A partir desse referencial, na dissertação de mestrado constatei que a história local, nas propostas curriculares municipais, foi traduzida prioritariamente como aquela que desenvolve análises da história da cidade. Ao analisar propostas curriculares de História para o ensino fundamental, de vários Estados brasileiros, elaboradas entre 1985 e 1995, percebeu ser praticamente consensual organizar os estudos da sociedade a partir da vivência dos alunos, para então introduzi-los em outras realidades (BITTENCOURT, 1998).

Dos 126 jovens participantes do estudo principal, 89 nasceram em Curitiba, sendo que 87 cursaram as séries inicias do ensino fundamental na rede pública de ensino do próprio município e 2 realizaram seus estudos na rede privada. Por outro lado, 37 nasceram em outras cidades, porém 23 estudaram as séries inicias do ensino fundamental na rede pública do município de Curitiba e 14 cursam as séries iniciais em redes públicas de outras cidades. Portanto, da amostra total, 110 estudaram as séries iniciais na rede pública do município de Curitiba e apenas 14 cursaram esse nível de ensino em redes públicas de outras cidades.

No que se refere aos conteúdos de história aprendidos nas séries iniciais do ensino fundamental os jovens responderam a seguinte questão: $\mathrm{O}$ que você aprendeu sobre a história de Curitiba quando cursou o ensino fundamental de $1^{\circ}$ a $4^{\circ}$ série. 
A questão foi respondida por 67jovens, a maioria dos jovens produziu uma lista de conteúdo, sistematizada no Quadro 1.

Quadro 1- Conteúdos da história de Curitiba indicados pelos jovens

\begin{tabular}{|l|l|l|}
\hline \multicolumn{1}{|c|}{ MAIS INDICADO } & \multicolumn{1}{|c|}{$\begin{array}{c}\text { MEDIANAMENTE } \\
\text { INDICADO }\end{array}$} & POUCO INDICADO \\
\hline Imigrantes: 10 & História dos Bairros: 3 & Nome da cidade: 2 \\
Fundação da cidade: 8 & Cidade ecológica: 3 & Colonização: 1 \\
Pontos turísticos: 6 & Símbolos: 3 & Tropeiros: 1 \\
População: 6 & Escravidão: 3 & Cidade histórica: 1 \\
Transporte coletivo: 6 & Cultura da cidade: 3 & Helena Kolody: 1 \\
Política: 5 & & Estrada de terra: 1 \\
Índios: 4 & & Idade da cidade: 1 \\
Parques: 4 & & \\
Qualidade de vida: 4 & & \\
Museu: 4 & & \\
\hline
\end{tabular}

Fonte: Autor

Apenas dois jovens responderam com um texto estruturado, Vanessa, de 18 anos, da escola C turma X, respondeu assim:

Não me lembro muito, mas a história de Curitiba... é muito antiga tinha outras culturas, no tempo tinha mais agricultores vindos de outros lugares como italianos, alemães, ucranianos, considerados grandes colaboradores para o crescimento da nossa Curitiba, muitos deles levam o nome de praças como praça do alemão, da Ucrânia e do J apão etc...

Carlos, 15 anos, também da escola $\mathrm{C}$ turma $\mathrm{X}$, respondeu a questão de outra maneira:

Que a cidade de Curitiba é muito antiga, fundada no ano de 1693 e também que aqui por muitos anos foi usado o trabalho escravo. Curitiba é a capital do Paraná, sendo também uma metrópole muito importante. Curitiba esteve sempre associada à cultura. De fato aqui nasceram grandes museus em homenagem a grandes nomes, também fundaram-se vários teatros e escolas para introduzir a arte. Curitiba é uma cidade muito organizada, mas como todas as outras cidades do mundo têm seus problemas. 
A observação dos dados (com a exceção da resposta dada pelo jovem Carlos) aponta para uma forte proximidade entre o tipo de passado apreendido pelos jovens na escola fundamental com o passado contado pela administração pública, como estratégia política de consolidar um determinado projeto de cidade, identificado com o discurso da cidade modelo. A relação pode ser percebida, quando os jovens acessam prioritariamente um passado da cidade formado pela presença do imigrante europeu. Como afirma Oliveira (2000), fazia parte do projeto de modernização urbano de Curitiba, desde a década de 1970, a associação entre o progresso da cidade e a imigração europeia. A valorização de determinadas etnias contribuiu na construção da imagem da cidade europeia, organizada e de primeiro mundo.

Além desse aspecto, na década de 1990, de acordo com a tese de doutorado de Ferreira (2008), havia uma intrínseca relação entre o projeto oficial de cidade e a proposta curricular da rede municipal de ensino. Conforme a autora, ao analisar o currículo oficial da rede municipal de Curitiba, constatou que o documento cumpriu uma função muito mais de reforçar as ideias e supostas verdades sobre a cidade ("cidade europeia", "um outro Brasil", "cidade modelo", de "planejamento urbano exemplar") do que questionar a cidade e o modo de vida do curitibano.

Ferreira (2008) analisou também a coleção de livros didáticos "Lições Curitibanas" distribuído aos alunos da rede municipal, no governo do prefeito Rafael Greca (1993-1996), e detectou a clara intenção do material de ensinar às crianças uma determinada Curitiba, idealizada, branca e exemplar. A autora destacou que alguns conteúdos tinham a intenção de promover a relação entre a História curitibana e o projeto de cidade evidenciado na década de 1990. Nessa direção, "os atores sociais que pensaram o projeto da cidade, na década de 1990, e mesmo, muitas décadas antes, operaram de sorte a resgatar, produzir ou mesmo forjar uma história”. (FERREIRA, 2008, p. 46) Estes atores selecionaram o passado que interessava, enfatizando alguns aspectos históricos, como fundação da cidade, o ascendente progresso nos século XVII e XVIII e a contribuição do imigrante europeu na formação cultural curitibana, em detrimento de outros, como o conflito entre colonizadores e indígenas no século XVI, à pobreza nos séculos XVII eXVIII e a presença do negro na formação social da cidade. A seleção do passado feita a serviço do projeto modernizador da cidade ainda rende seus frutos, visto que os jovens da minha investigação consideraram, na questão 16, a imagem da ocupação a menos representativa da cidade e destacaram, nas primeiras posições, símbolos da cidade espetáculo, como o Jardim Botânico e o Parque Barigui, constituídos pelo discurso hegemônico e pouco crítico sobre a cidade. 


\section{Considerações Finais}

Em termos prospectivos considero importante apontar as seguintes considerações:

1 a necessidade de ampliar, em futuras investigações, os sujeitos envolvidos na pesquisa, particularmente os professores e a forma como se relacionam com o passado da cidade de Curitiba, articulando com sua maneira de ensiná-lo;

2 investigações que contemplem a observação da presença de narrativas sobre a cidade de Curitiba em manuais didáticos e em aulas do ensino fundamental;

3 estudos comparativos envolvendo outras cidades, no sentido de verificar as especificidades e/ ou universalidades.

Revelo que este trabalho, a partir das considerações apontadas insere-se no domínio científico da Educação Histórica e, pelo substrato teórico que fundamenta esse campo, apontou importantes contribuições, tais como a complexa relação da formação da consciência histórica e das identidades. Ademais, indicou que essa relação pensada de maneira concreta, isto é, a partir da relação entre teoria e a vida humana prática do seu tempo, pode ser fundamental para subsidiar a articulação entre a cultura local e a cultura escolar, particularmente no que se refere à presença da história das cidades em manuais didáticos e propostas curriculares.

\section{Referências}

ANGVIK, M.; BORRIES, B. Youth and history: a comparative European survey on historical and political attitudes among adolescents. Hamburg: Korber Foundation, 1997. v. A, B).

BARCA, Isabel. Educação histórica: uma nova área de investigação? In: ENCONTRO NACIONAL DE PESQUISADORES DE ENSINO DE HISTÓRIA, 6., 2005, Londrina. Anais... Londrina: Atrito Art, 2005. p. 15- 25. . Educação histórica: pesquisar o terreno, favorecer a mudança. SCHMIDT,

Maria A.; BARCA, Isabel (Org.) Aprender história: perspectivas da educação histórica. Ijuí: Ed. Unijuí, 2009. . Marcos de consciência histórica de jovens portugueses. Currículo sem fronteiras, Porto Alegre, v. 7, n. 1, p. 115-126, jan./jun., 2007. 
BITTENCOURT, Circe M. F. Propostas curriculares de história: continuidade é transformações. In: BARRETO, E. (Org.) Os currículos do ensino fundamental para as escolas brasileiras. São Paulo: Autores associados, 1998.

BRASIL. Secretária de Educação Fundamental. Parâmetros Curriculares Nacionais: história e geografia. Rio de J aneiro: DP\&A, 2000.

CHEVALLARD, Yves. La transposición didáctica: del saber sabio al saber a ser ensinado. Argentina: Aique,1997.

FERREIRA, Valéria M. R. Tecendo uma cidade modelar: relações entre currículo, educação escolar e projeto da cidade de Curitiba na década de 1990. 2008. $261 \mathrm{f}$. Tese (Doutorado em Educação) - Programa de Estudos Pós-Graduados em Educação: História, Política, Sociedade, Pontifícia Universidade Católica de São Paulo, São Paulo, 2008.

GARCIA, F. E. S. Cidade espetáculo: política, planejamento e city marketing. Curitiba: Palavra, 1997.

HALL, Stuart. A identidade cultural na pós-modernidade. Rio de J aneiro: DP\&A, 2005.

J UNG, H.; STAHER, G. Didáctica de la história y enseñanza de la historia em la Alemania unificada. Revista Conciencia social. Madrid, n. 2, p. 133-148, 1998.

MARTUCCELLI, Danilo. Gramáticas del individuo. Traducido de J osé Federico Delos. Buenos Aires: Losada, 2007.

OLIVEIRA, Dennison de. Curitiba e o mito da cidade modelo. Curitiba: Ed da UFPR, 2000.

OLIVEIRA, Márcio de. A trajetória do discurso ambiental em Curitiba (1960-2000). Revista de Sociologia Política. Curitiba, n. 16, p. 97-106, jun. 2001.

PAIS, J osé Machado. A consciência histórica e identidade: os jovens portugueses num contexto europeu. Oeiras: Celta, 1999.

RÜSEN, Jörn. El desarrollo de la competencia narrativa en el aprendizaje histórico: una hipótesis ontogenética relativa a la conciencia moral. Trad. Silvia Finocchio. Propuesta Educativa, Argentina, n. 7, out. 1992. Brasília: UnB, 2001.

. Razão histórica: teoria da história: fundamentos da ciência histórica.

SCHMIDT, Maria A. Contribuições ao estudo da construção da didática da história como disciplina escolar no Brasil: 1935-1952. In: CONGRESSO LUSO-BRASILEIRO DE HISTÓRIA DA EDUCAÇÃO, 6., 2006, Uberlândia. Anais... Uberlândia: UFU, 2006. p. 4100-4109. Disponível em:

<www.faced.ufu.br/ colubhe06/ anais/arquivos/ eixo6.htm>. Acesso em: 27jan. 2010.

. J ovens brasileiros e europeus: identidade, cultura e ensino de história (19982000). Revista Perspectiva, Florianópolis, v. 20, n. Especial, p. 183-208, jul./ dez. 2002. 
SCHMIDT, Maria A.; GARCIA, Tânia M. F. A formação da consciência histórica de alunos e professores e o cotidiano em aulas de história. Cad. Cedes, Campinas, v. 25, n. 67, p. 297-308, set./ dez. 2005.

Discutindo o currículo "por dentro" contribuições da pesquisa etnográfica. Educar, Curitiba, n. 17, p. 139-149, 2001.

SOUZA, Nelson R. de. Planejamento urbano em Curitiba: saber técnico, classificação dos citadinos e partilha da cidade. Revista Sociologia Política, Curitiba, v. 16, p. 107-122, jun. 2001. 